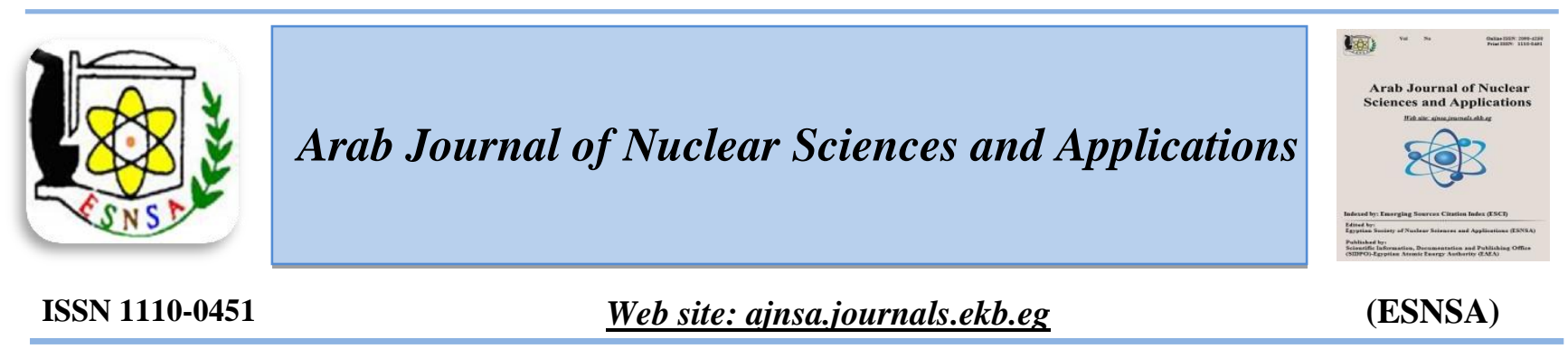

\title{
The Relation between Anti-Müllerian Hormone with Antral Follicle Count and Ovarian Volume in Polycystic Ovary Syndrome
}

\author{
Hanan Mohamed Gabr and Elham Sayed Marei \\ Health Radiation Research Department, National Center for Radiation Research and Technology, Egyptian Atomic \\ Energy Authority
}

Received $2^{\text {nd }}$ May 2018
Accepted $22^{\text {nd }}$ Feb. 2019

Received 2 ${ }^{\text {nd }}$ May 2018
Accepted $22^{\text {nd }}$ Feb. 2019

Polycystic ovary syndrome (PCOS) is the most common endocrinopathy in women during reproductive age. Women with PCOS show raised Anti-Müllerian hormone (AMH) levels, due to increased number of small antral follicles and granulosa cells, and these may lead to anovulation. Measuring antral follicle count (AFC) and ovarian volume (OV) by ultrasound scanning gives insight to the ovarian function. This study is conducted to investigate the relation between $\mathrm{AMH}$ with $\mathrm{AFC}, \mathrm{OV}$ and different biochemical parameters which determine PCOS. The study was carried out on thirty patients with PCOS as (group 1) compared with fifteen healthy women as control group (group 2). AMH, FBS, Insulin, HOMA/IR, Testosterone, cholesterol, Triglycerides (TG), body mass index (BMI) and hirsutism were measured for all women in both groups. The results revealed that the serum level of AMH is significantly higher in PCOS (11.90 $\pm 4.23 \mathrm{ng} / \mathrm{ml})$ than control group (4.36 $\pm 0.56 \mathrm{ng} / \mathrm{ml})$. As for AFC, there is high significant increase (26.10 \pm 5.49 follicles) in PCOS group versus $(9.07 \pm 1.83$ follicles) in control group. Furthermore, the results revealed a highly significant difference in $\mathrm{OV}(\mathbf{1 1 . 2 0} \pm \mathbf{2 . 7 8 m})$ in $P C O S$ compared to $(6.23 \pm 0.73 \mathrm{ml})$ in control. There is a significant correlation between $\mathrm{AMH}, \mathrm{AFC}$ and $\mathrm{OV}$ in PCOS. There is a high significant correlation between AMH, AFC, OV, BMI testosterone, HOMA/IR, HDL, cholesterol, and TG in both groups. It could be concluded that there is a tight positive correlation between AMH and AFC and OV.

Keywords: Polycystic ovary syndrome (PCOS), Anti-Müllerian hormone (AMH), antral follicle count (AFC), ovarian volume syndrome (OVS)

\section{Introduction}

Polycystic ovary syndrome (PCOS) is the most common endocrine disorder among women affecting $6-21 \%$ of reproductive aged women, which represents the main cause of infertility [1, 2]. According to the Rotterdam consensus, two out of three criteria are required for the diagnosis of this syndrome: oligo- or anovulation, clinical or biochemical hyperandrogenism and/or polycystic ovaries on ultrasound. It can also be associated with insulin resistance, obesity and altered gonadotrophin release [3].

The clinical implications of ovulatory dysfunction in PCOS include infertility, obesity, and increased prevalence of endometrial hyperplasia and cancer
[4]. Altered quality of life is another consequence of PCOS due to infertility, obesity and hirsutism. However, in particular patients, altered menstrual cycles cause psychological disturbances which should be considered when deciding the treatment of a PCOS patient [5]. The wide range and frequency of symptoms made it difficult to establish a consistent clinical picture, which may change at different times of life [6].

Traditionally the absolute level of $\mathrm{LH}$ and FSH, as well as the LH/FSH ratio, may offer significant insight into the PCOS patient, but is not accurate. It is clear that $\mathrm{AMH}$ is a diagnostic marker of ovarian function and increased AMH levels correlated with PCOS [7]. The Anti-Müllerian

Corresponding author: hanangabr62@gmail.com

DOI: 10.21608/ajnsa.2019.3711.1087

(C) Scientific Information, Documentation and Publishing Office (SIDPO)-EAEA 
hormone $(\mathrm{AMH})$ is produced by the granulosa cells in the premature ovarian follicles until they become sensitive to FSH. Its level is constant during the menstrual cycle as the primordial follicles, the dominant follicle and corpus luteum don't secrete $\mathrm{AMH}[8,9]$. The intra-follicular concentration of AMH depends on the follicle size [10]. AMH can be used as an indication for the remnant follicle pool because it is mainly produced by the small antral follicles [11]. AMH peaks when women are in their early twenties [12]. Later in life, it decreases until menopause which is no longer detectable [13].

Ovarian morphology must be assessed by transvaginal ultrasound which is accurate, although abdominal ultrasounds may be used in the case of young girls or in virgins with less accuracy of ovarian morphology assessment and calculation of the number of small follicles. Hyperandrogenism and insulin resistance in PCOS stop the follicle development and the resulting follicle arrest contributes to PCO morphology where small antral follicles are lined in ovarian periphery [14].

The present study was designed to clarify the correlation of $\mathrm{AMH}$ with $\mathrm{AFC}$ and $\mathrm{OV}$ in women with PCOS and in controls.

\section{Patients and Methods}

This case-control study was carried out on 30 PCOS patients and 15 healthy women in the middle age group. The study was conducted from June to December 2016 in Ain Shams Maternity Hospital. All participants gave written informed consent, and the procedures followed were in accordance with the ethical standards of the hospital and approved from the ethical committee of National Center for Radiation Research and Technology. The studied subjects were classified into two groups. PCOS group: thirty women with PCOS were characterized by $(\mathrm{OA}+\mathrm{HA}+\mathrm{PCOM})$. Oligo-anovulation (OA) was defined as selfreported menstrual cycle length of $\geq 35$ days or $<$ 10 menstrual periods per year. Clinical hyperandrogenism (HA) was defined by scoring terminal hair growth on nine body sites from 0-4 at each site according to Ferriman-Gallwey (FG score), Hirsutism has been usually graded as mild up to a score of 15 , moderate from 16 to 25 , and severe above 25 . Biochemical HA was defined as serum testosterone $>2.5 \mathrm{nmol} / \mathrm{l}$.

\section{Control group:}

fifteen women with regular menstrual cycles, no clinical or biochemical hyperandrogenism and normal ovaries on ultrasound. Subjects with history of ovarian surgery or treated with cytotoxic drugs or pelvic radiation, received hormonal therapy within three months before the beginning of the study, or had another endocrinological disorder were excluded.

Diagnosis of PCOS was based on Rotterdam criteria with two of 1-irregular menstrual cycles (oligoanovulation) OA ( $\geq 35$ days), 2-clinical (hirsutism, acne) or biochemical hyperandrogenism (HA) (increase in at least one circulating ovarian androgen) and 3-PCOM on ultrasound and with exclusion of related disorders [15]. The existing Rotterdam guidelines suggest that PCOM is indicated by the presence of at least 12 follicles measuring 2 to $9 \mathrm{~mm}$ in the whole ovary or by the finding of increased ovarian size $(>10 \mathrm{~mL})[16]$.

Patients and controls were subjected to: 1Complete history taking to clarify irregularity of menstrual cycles. Il- Clinical examination was conducted for all participants to detect the relevant data as the degree of hirsutism, weight and height. Ill- Ultrasonography: AFC and OV were diagnosed by ultrasound which was performed with General Electric Logiq Book XP with vaginal probe 7.5 $\mathrm{MHz}$ (General Electric Medical Systems). Ovarian size was measured in three dimensions, and the volume was subsequently calculated by the formula: (height $\times$ width $\times$ depth $\times 0.5$ ). All visible follicles of $2-9 \mathrm{~mm}$ in diameter in both ovaries were included in the AFC. All ultrasound examinations were performed by the same investigator. IV-Laboratory investigations: for all subjects, blood was withdrawn by syringe; serum was separated after clotting by centrifugation; placed in aliquots and stored at $-20^{\circ} \mathrm{C}$ till the assay of the hormones. Hormones were measured during the follicular phase in controls and if possible in PCOS. In those with irregular cycles, this was not always possible; however, AMH does not vary considerably across the menstrual cycle [17]. AMH was analyzed using an ELISA kit (MBS 702605, My Biosource Company, USA) in a single batch from frozen serum.

Testosterone was measured on Beckman Coulter Unicel DXI 800 analyzer (Beckman Coulter Diagnostics Australia, Gladesville, Australia) using an automated competitive binding 
immunoenzymatic assay. Fasting plasma glucose and fasting insulin, cholesterol, high-density lipoprotein cholesterol (HDL-C), and triglycerides (TG) were measured using an enzymatic colorimetric method (BIOLABO REAGENTS SA 02160, Maizy, France).

Fasting glucose and insulin were measured to calculate homoeostatic model of insulin resistance (HOMA-IR) [18]. HOMA-IR was calculated as fasting serum insulin $(\mathrm{mIU} / \mathrm{l}) \times$ fasting blood glucose $(\mathrm{FBG})(\mathrm{mmol} / \mathrm{l}) / 22 \cdot 5]$.

\section{Statistical analysis}

Results were presented as mean \pm SD. Differences between the two groups (PCOS and control) were determined using an independent test. Relationships between variables were assessed using two-tailed Pearson's correlation coefficient (r). All statistical analysis were performed using SPSS for Windows 20.0 software (SPSS Inc, version 20.0 software, Chicago, IL, USA) with statistical significance accepted when $P<0 \cdot 05$.

\section{Results}

The results are demonstrated in Tables and Figures as follows: Table (1) shows the statistically significant differences between control and PCOS groups as regards different measured parameters. Table (2) shows a correlation between AMH and all parameters studied in PCOS group. There is a high significant direct correlation between AMH, $\mathrm{AFC}$ and $\mathrm{OV}$, but non-significant correlation between $\mathrm{AMH}$, age, BMI, hirsutism, testosterone, FBS, Insulin, HOMA/IR, cholesterol, HDL and TG. Table (3) shows that in both groups there is high significant direct correlation between $\mathrm{AMH}$ and Testosterone, HOMA/IR, BMI, cholesterol , HDL with $\mathrm{p}=.000$ and significant correlation with TG. Table (4) shows high significant direct correlation of AMH with AFC and $\mathrm{OV}$ in both groups with $\mathrm{p}=0.000$ in both groups.

Table (1): Mean \pm Standard deviation of clinical, biochemical, hormonal and ultrasonographic parameters in both groups

\begin{tabular}{|c|c|c|c|}
\hline Parameters & $\begin{array}{c}\text { Control }(n=15) \\
\text { Mean } \pm \text { SD }\end{array}$ & $\begin{array}{c}\operatorname{PCOS}(n=30) \\
\text { Mean } \pm \text { SD }\end{array}$ & $P$-values \\
\hline Age(years) & $28.20 \pm 4.31$ & $27.80 \pm 4.10$ & NS \\
\hline BMI $\left(\mathbf{k g} / \mathbf{m}^{2}\right)$ & $27.44 \pm 1.73$ & $34.78 \pm 3.43$ & $<0.0001$ \\
\hline Hirsutism & $7.73 \pm 1.66$ & $26.49 \pm 3.6$ & $<0.0001$ \\
\hline FBG(mmol/l) & $5.08 \pm 0.99$ & $5.98 \pm 1.16$ & $<0.05$ \\
\hline Insulin(mIU/l) & $13.02 \pm 2.44$ & $23.21 \pm 5.91$ & $<0.0001$ \\
\hline HOMA /IR & $2.74 \pm 0.42$ & $6.21 \pm 2.49$ & $<0.0001$ \\
\hline Cholesterol(mg/dl) & $167.66 \pm 17.19$ & $217.74 \pm 20.96$ & $<0.0001$ \\
\hline TG (mg/dl) & $84.00 \pm 8.83$ & 98.76 \pm 13.97 & $<0.001$ \\
\hline HDL(mg/dl) & $55.80 \pm 4.53$ & $39.45 \pm 7.25$ & $<0.0001$ \\
\hline Testosterone(ng/ml) & $0.301 \pm 0.13$ & $0.856 \pm 0.30$ & $<0.0001$ \\
\hline AMH (ng/ml) & $4.36 \pm 0.56$ & $11.90 \pm 4.23$ & $<0.0001$ \\
\hline AFC (follicle) & $9.06 \pm 1.83$ & $26.10 \pm 5.49$ & $<0.0001$ \\
\hline $\mathrm{OV}(\mathrm{ml})$ & $6.23 \pm 0.73$ & $11.30 \pm 2.78$ & $<0.0001$ \\
\hline
\end{tabular}


Table (2): Correlation between AMH and all parameters studied in PCOS group shows a highly significant direct correlation between AMH, AFC and OV but non-significant correlation between AMH and BMI, Hirsutism, Testosterone, FBS, Insulin, HOMA/IR, Cholesterol, HDL, and TG

\begin{tabular}{|c|c|c|c|}
\hline Pearson correlation & Age & BMI & Hirsutism \\
\hline AMH & -0.017 & -0.126 & 0.092 \\
\hline$p=$ & 0.972 & 0.507 & 0.629 \\
\hline Pearson correlation & AFC & $\mathbf{O V}$ & Testosterone \\
\hline AMH & 0.879 & 0.853 & 0.063 \\
\hline$p=$ & 0.000* & 0.000* & 0.740 \\
\hline Pearson correlation & FBS & Insulin & HOMA/IR \\
\hline AMH & 0.177 & 0.211 & 0.265 \\
\hline$p=$ & 0.350 & 0.262 & 0.157 \\
\hline Pearson correlation & Cholesterol & HDL & TG \\
\hline AMH $\quad r=$ & 0.101 & -0.137 & -0.112 \\
\hline$p=$ & 0.595 & 0.470 & 0.557 \\
\hline
\end{tabular}

Table (3): Correlation between AMH and Testosterone, HOMA/IR, BMI, cholesterol, HDL and TG in both

\begin{tabular}{|c|c|c|c|c|c|c|c|c|}
\hline Parameter & $\begin{array}{c}\text { Pearson } \\
\text { Correlation }\end{array}$ & AMH & $\begin{array}{l}\text { HOM } \\
\text { A/IR }\end{array}$ & BMI & $\begin{array}{c}\text { Testost } \\
\text { erone }\end{array}$ & $\begin{array}{c}\text { Choles } \\
\text { terol }\end{array}$ & HDL & TG \\
\hline AMH & $\begin{array}{l}\mathbf{r}= \\
\mathbf{P}=\end{array}$ & 1 & $\begin{array}{l}.581^{* * *} \\
.000\end{array}$ & $\begin{array}{l}.494^{* *} \\
.001\end{array}$ & $\begin{array}{l}.552^{* *} \\
.000\end{array}$ & $\begin{array}{l}.594^{* * *} \\
.000\end{array}$ & $\begin{array}{c}-.608-^{* *} \\
.000\end{array}$ & $\begin{array}{l}.286 \\
.050\end{array}$ \\
\hline HOMA/IR & $\begin{array}{l}\mathbf{r}= \\
\mathbf{P}=\end{array}$ & $\begin{array}{l}.581^{* *} \\
.000\end{array}$ & 1 & $\begin{array}{l}.592^{* *} \\
.000\end{array}$ & $\begin{array}{l}.384^{* *} \\
.009\end{array}$ & $\begin{array}{l}.649^{* * *} \\
.000\end{array}$ & $\begin{array}{c}-.442-^{* *} \\
.002\end{array}$ & $\begin{array}{l}.199 \\
.189\end{array}$ \\
\hline BMI & $\begin{array}{l}r= \\
P=\end{array}$ & $\begin{array}{l}.494^{* *} \\
.001\end{array}$ & $\begin{array}{l}.592^{* *} \\
.000\end{array}$ & 1 & $\begin{array}{l}.578^{* *} \\
.000\end{array}$ & $\begin{array}{l}.631^{* *} \\
.000\end{array}$ & $\begin{array}{c}-.561-^{* * *} \\
.000 \\
\end{array}$ & $\begin{array}{l}.448^{* *} \\
.002 \\
\end{array}$ \\
\hline Testosterone & $\begin{array}{l}\mathbf{r}= \\
\mathbf{P}=\end{array}$ & $\begin{array}{l}.552^{* *} \\
.000\end{array}$ & $\begin{array}{l}.384^{* *} \\
.009\end{array}$ & $\begin{array}{l}.578^{* *} \\
.000\end{array}$ & 1 & $\begin{array}{l}.376^{*} \\
.011\end{array}$ & $\begin{array}{c}-.584-^{* * *} \\
.000\end{array}$ & $\begin{array}{l}.417^{* *} \\
.004\end{array}$ \\
\hline Cholesterol & $\begin{array}{l}\mathbf{r}= \\
\mathbf{P}=\end{array}$ & $\begin{array}{l}.594^{* *} \\
.000\end{array}$ & $\begin{array}{l}.649^{* *} \\
.000\end{array}$ & $\begin{array}{l}.631^{* *} \\
.000\end{array}$ & $\begin{array}{l}.376^{*} \\
.011\end{array}$ & 1 & $\begin{array}{c}-.494-^{* *} \\
.001\end{array}$ & $\begin{array}{l}.233 \\
.124\end{array}$ \\
\hline HDL & $\begin{array}{l}\mathbf{r}= \\
\mathbf{P}=\end{array}$ & $\begin{array}{c}-.608-^{* *} \\
.000 \\
\end{array}$ & $\begin{array}{c}-.442-^{* *} \\
.002 \\
\end{array}$ & $\begin{array}{c}-.561-^{* *} \\
.000 \\
\end{array}$ & $\begin{array}{c}-.584-^{* *} \\
.000 \\
\end{array}$ & $\begin{array}{c}-.494-^{* *} \\
.001 \\
\end{array}$ & 1 & $\begin{array}{c}-.500-^{* *} \\
.000 \\
\end{array}$ \\
\hline TG & $\begin{array}{l}\mathbf{r}= \\
\mathbf{P}=\end{array}$ & $\begin{array}{l}.286 \\
.050\end{array}$ & $\begin{array}{l}.199 \\
.189\end{array}$ & $\begin{array}{l}.448^{* *} \\
.002\end{array}$ & $\begin{array}{l}.417^{* *} \\
.004\end{array}$ & $\begin{array}{l}.233 \\
.124\end{array}$ & $\begin{array}{c}-.500-^{* *} \\
.000\end{array}$ & 1 \\
\hline
\end{tabular}


Table (4) Correlation of AMH with AFC and OV in both groups which show a highly significant direct correlation

\begin{tabular}{|l|c|c|c|c|}
\hline \multicolumn{2}{|c|}{ Pearson Correlation } & AMH & AFC & Ov. Vol \\
\hline \multirow{2}{*}{ AMH } & $r=$ & 1 & $.902^{* *}$ & $.951^{* * *}$ \\
& $P=$ & & .000 & .000 \\
AFC & $r=$ & $.902^{* *}$ & 1 & $.903^{* *}$ \\
\multirow{2}{*}{ Ov. Vol } & $P=$ & .000 & & .000 \\
& $r=$ & $.951^{* *}$ & $.903^{* *}$ & 1 \\
& $P=$ & .000 & .000 & \\
\hline
\end{tabular}

Figure (1) shows a highly significant direct correlation between AMH and AFC in PCOS group $\mathrm{p}<0.001$. Figure (2) shows a highly significant direct correlation between $\mathrm{AMH}$ and Ovarian volume in PCOS group $p<0.001$. Figure
(3) shows ROC curve for AMH shows area under the curve $=1$, cut off value for $A M H$ which diagnose PCOS is 5.80 with sensitivity $=100 \%$ and specificity $100 \%$. Figure (4) shows AFC and OV in Ultrasound images.

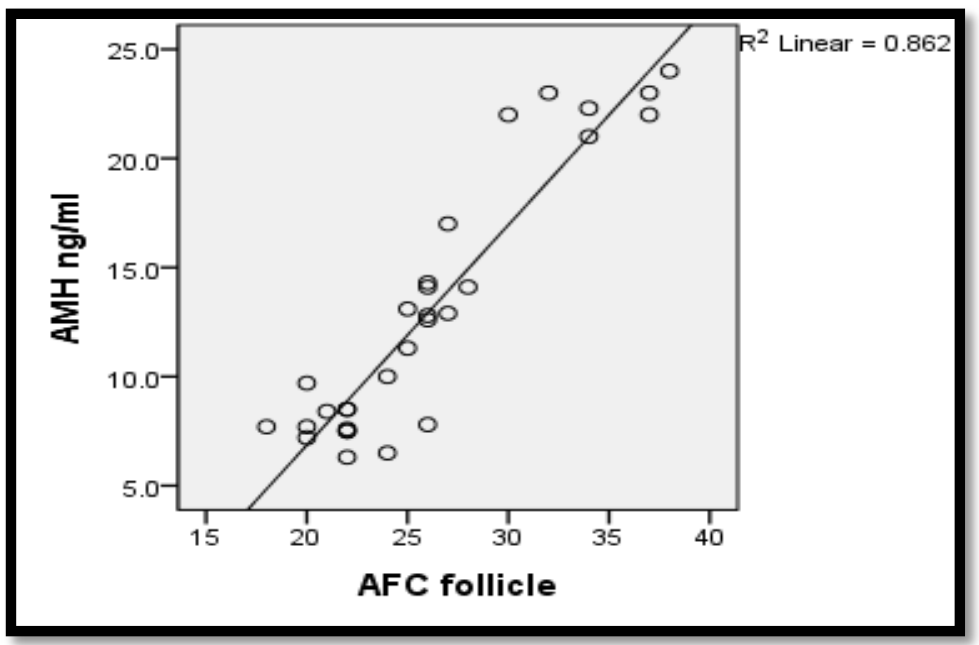

Figure (1): Correlation between AMH and AFC in PCOS group which show direct significant correlation with $\mathbf{r}^{2}=0.862$ and $p<0.001$

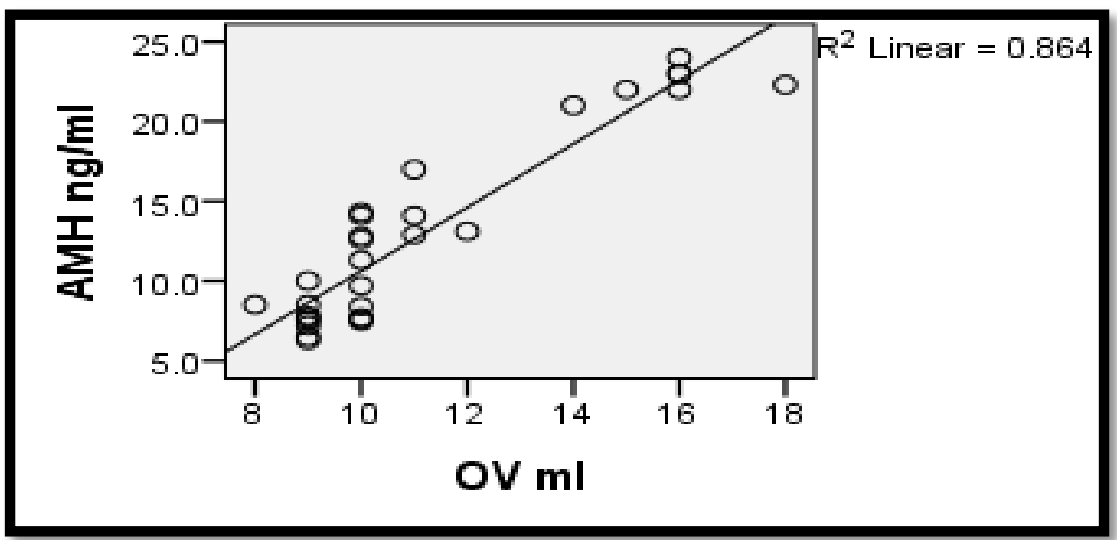

Figure (2): Correlation between AMH and Ovarian volume in PCOS group which show direct significant correlation with $\mathbf{r}^{2}=\mathbf{0 . 0 8 6 4}$ and $\mathbf{p}<0.001$ 


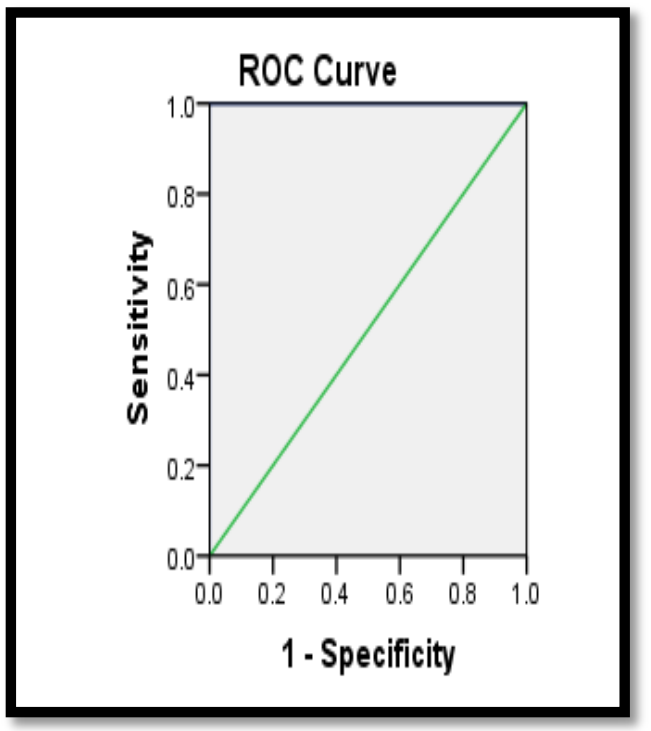

\begin{tabular}{|c|c|c|}
\hline $\begin{array}{c}\text { positive if } \\
\text { greater than or } \\
\text { equal to }\end{array}$ & sensitivity & 1 - specificity \\
\hline 4.5500 & 1.000 & .400 \\
\hline 4.6500 & 1.000 & .267 \\
\hline $\mathbf{5 . 0 0 0 0}$ & 1.000 & .067 \\
\hline $\mathbf{5 . 8 0 0 0}$ & $\mathbf{1 . 0 0 0}$ & .000 \\
\hline $\mathbf{6 . 4 0 0 0}$ & .967 & .000 \\
\hline $\mathbf{6 . 8 5 0 0}$ & .933 & .000 \\
\hline 7.3500 & .900 & .000 \\
\hline 7.5500 & .833 & .000 \\
\hline 7.6500 & .800 & .000 \\
\hline 7.7500 & .733 & .000 \\
\hline
\end{tabular}

Figure (3): ROC curve for AMH shows area under the curve=1, cut off value for AMH which diagnose PCOS is 5.80 with sensitivity $=100 \%$ and specificity $100 \%$
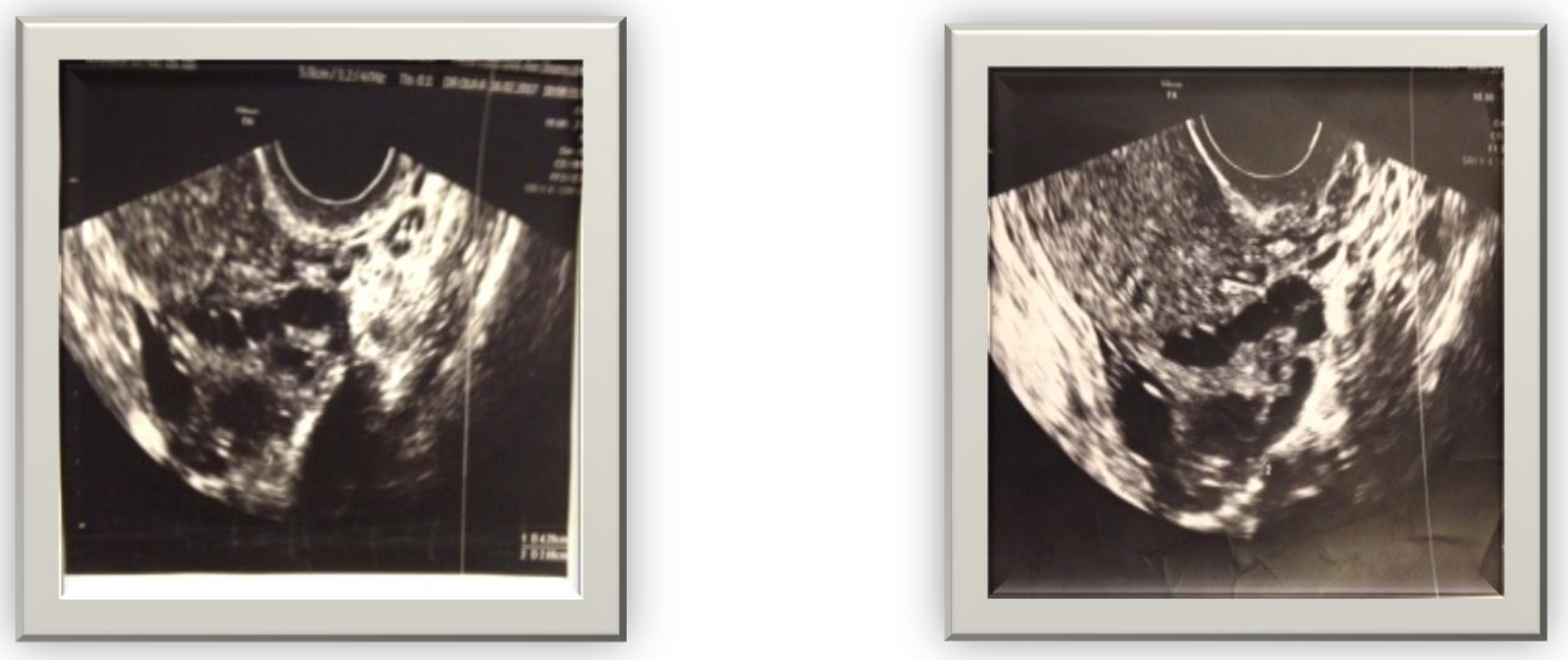

Figure (4): AFC and OV in PCOS

Discussion

Polycystic ovary syndrome is a collection of signs and symptoms varying from mild to severe and affecting the reproductive, endocrine and metabolic functions [19] PCOS is one of the leading causes of female sub-fertility [20] and the most frequent endocrine problem in women of reproductive age [21]. Despite many decades of extensive research, the exact etiology and pathogenesis of this complex disorder remain still hidden. AMH is a promising marker as its level is constant throughout the menstrual cycle and not influenced by fluctuations in other reproductive hormones [22].

The present study was carried out to examine the relation between serum levels of AMH with Antral follicle count and ovarian volume in PCOS patients and comparing them with healthy women. The foregoing results of this study confirmed that fasting Blood glucose in PCOS group (5.98 $\pm 1.16 \mathrm{mmol} / \mathrm{L})$ is significantly higher than in control group $(5.09 \pm 0.99 \mathrm{mmol} / \mathrm{L})$. There is 
significantly high insulin level $(23.21 \pm 5.91$ $\mathrm{mIu} / \mathrm{L})$ in PCOS than in control group (13.02 \pm $2.44 \mathrm{mIu} / \mathrm{L})$.

This study confirmed that HOMA/IR is $(6.21 \pm$ 2.49) in PCOS group which is significantly higher compared to $(2.74 \pm 0.42)$ in control group. The results of the present study show highly significant direct correlation between HOMA/IR and cholesterol, which is consistent with the results of Lee et al. who showed a significant correlation between HOMA-IR and TG, LDL and HDL cholesterol [23]. In our study the cutoff value for HOMA/IR $\geq 3.22$ with sensitivity $87.3 \%$ and specificity $87.3 \%$ which is consistent with a recent research by Alebić et al. who investigated whether insulin resistance in PCOS is exclusively associated with BMI and suggested specific HOMA-IR cutoff value $\geq 3.15$ for PCOS [24].

Insulin resistance (IR) is the most common etiological factor in women with PCOS and that (IR) causes the generation of increased oxidative stress and diminished antioxidant status [25]. As for regards hirsutism, there is a significantly higher Ferriman-Gallwey (mFG) score in PCOS $(26.49 \pm 3.6)$ than that in the control $(7.73 \pm 1.66)$ with a cutoff value of $\geq 15.7$ with a $100 \%$ sensitivity and $100 \%$ specificity. Some authors [26] have reviewed many published results and some of them reported a cutoff value of $\mathrm{mFG}$ score of $\geq 11$ for white Middle Eastern women [27]. Androgen excess disorders may be present with normal body hair; hence the absence of hirsutism does not exclude the consideration of PCOS in which other features of androgen excess, such as acne, alopecia, infertility or menstrual dysfunction are present [28].

The mean cholesterol level is significantly higher in the PCOS group $(217.74 \pm 20.96 \mathrm{mg} / \mathrm{dl})$ than that in the control group $(167.66 \pm 17.19 \mathrm{mg} / \mathrm{dl})$. The mean triglycerides level shows a significant increase in PCOS $(98.76 \pm 13.97 \mathrm{mg} / \mathrm{dl})$ versus $(84.00 \pm 8.83 \mathrm{mg} / \mathrm{dl})$ in control group. In this study the mean HDL level is significantly lower in the PCOS group $(39.45 \pm 7.25 \mathrm{mg} / \mathrm{dl})$ which indicates high risk level in this group compared with control group $(55.80 \pm 4.53 \mathrm{~m}(\mathrm{~g} / \mathrm{dl})$ which indicates a low risk level of HDL. This is consistent with the results of Gambineri et al. who stated that low HDL-cholesterol is the criterion which best explains the high prevalence of the metabolic syndrome in PCOS subjects and is influenced by hyperinsulinemia, rather than by hyperandrogenemia [29]. In the current study the BMI show a significant increase in PCOS $\left(34.78 \pm 3.43 \mathrm{Kg} / \mathrm{m}^{2}\right)$ compared with control $\left(27.44 \pm 1.73 \mathrm{Kg} / \mathrm{m}^{2}\right)$ and is significantly directly correlated with AMH in all subjects.

Moran et al. found that exercise decreases AMH in overweight women with polycystic ovary syndrome [30]

In the present study, the serum level of AMH in PCOS $(11.90 \pm 4.23 \mathrm{ng} / \mathrm{ml})$ is significantly higher than in control group $(4.36 \pm 0.56 \mathrm{ng} / \mathrm{ml})$ and these results agreed with that of Dewailly et al. who found that elevated AMH values $(>4.5 \mathrm{ng} / \mathrm{ml})$ may be useful as a substitute for ovarian morphology when no accurate ovarian ultrasound is available [31]. In this study, the AMH mean level is elevated 2.72 fold in the PCOS patients in comparison with normal subjects. This is in agreement with the findings of previous researchers [7, 32] who reported that $\mathrm{AMH}$ serum levels are elevated 2- to 3 - fold in women with the PCOS in comparison with normo-ovulatory women, consistent with the increased number of small antral follicles in the PCOS. Additionally, Piltonen et al. found that serum levels of anti-Müllerian hormone were higher in patients with PCOS than in normal women [33]. The present study showed that serum AMH cutoff level of $5.8 \mathrm{ng} / \mathrm{ml}$ can diagnose PCOS patient with sensitivity $100 \%$ and specificity $100 \%$. Lin et al. obtained the cutoff AMH level of $7.3 \mathrm{ng} / \mathrm{mL}$, giving $76 \%$ specificity and $70 \%$ sensitivity to predict PCOS [34]. On the other hand, Wiweko et al. [35] obtained a cutoff value of $4.45 \mathrm{ng} / \mathrm{mL}$ which is lower than the findings of Lin et al. [34]. In addition, measurement of serum AMH levels may also be used as an indicator of PCOS patients' response to therapeutic approaches [30] and evaluation after treatment with insulin sensitizers [33], and monitoring after laparoscopic ovarian drilling [36].

The results of this study demonstrated that AFC mean counted, in both ovaries in PCOS group (26.10 \pm 5.49 follicles), is significantly higher than that in the control group (9.06 \pm 1.83 follicles). These data are consistent with those of Chen et al. [37] who confirmed $\geq 12$ as threshold for follicle number per ovary (FNPO) in the Chinese women, whereas Kosus et al. [38] proposed an FNPO threshold of 8 follicles per ovary for Turkish women. The 2003 Rotterdam consensus, the most common ultrasound definition employed to date, was based on the Balen et al. study and on expert 
agreement [16]; Distinguishing PCOS cases from controls as judged by transvaginal Ultrasonography, with an FNPO threshold of $\geq 12$ follicles measuring 2-9 $\mathrm{mm}$ in diameter (mean of both ovaries) were established by many authors [31, 39]. Moreover, Dewailly et al. [31] applied cluster analysis in order to exclude clinically normal women with PCOM prior to determining the threshold for FNPO. Their analysis would have yielded a cut-off value of 25 follicles.

These results are similar to the results obtained by Lujan et al. [39]. Moreover, Dewailly et al. added that the value of $\mathrm{AMH}$ in the diagnosis of PCOS may replace AFC in the future [40]. This is consistent with our study in which there is high significant correlation between AMH and AFC with $\mathrm{r}=0.879$ and $\mathrm{P}<0.0001$ in PCOS group, depending on this powerful correlation we can rely on clinical picture plus serum AMH without AFC to diagnose PCOS.

As for the ovarian volume, there is a higher significant increase in the PCOS group reaching $\left(11.30 \pm 2.78 \mathrm{~cm}^{3}\right)$ versus $\left(6.23 \pm 0.73 \mathrm{~cm}^{3}\right)$ in the control group, and there is high significant correlation between AMH and OV with $\mathrm{r}=0.853$ and $\mathrm{P}<0.0001$ in PCOS. In agreement with the present findings, a relevant study by Koutlaki et al. demonstrated that AMH had a statistically significant positive correlation with the ovarian volume with $(\mathrm{r}=0,623, \mathrm{P}<0.01)$ [41]. In a recent study, the ovarian volume showed the strongest positive correlation $(\mathrm{r}=0.62)$ with the serum AMH level among related factors [42]. In the present study there is also a highly significant correlation between AFC and OV with $(\mathrm{r}=0.861, \mathrm{P}<0.0001)$. This study shows a ratio of AMH/AFC as 0.46 in PCOS and 0.48 in controls which gives an estimation of AMH amount per each follicle. Hence, the number of the follicles from the serum level of AMH can be estimated. In agreement with our results, Laven et al. found significant relationships between serum $\mathrm{AMH}$ levels and increasing testosterone, increase in number of follicles and the ovarian volume on ultrasound examination [32]. The highly significant correlation between AMH and AFC in PCOS, in the present study, shows an agreement with the findings of Lin et al., who reported that if at some time, ultrasound scanning cannot provide accurate data; the levels of AMH may be used to replace the number of follicles as a diagnostic criterion [34]. Zhang et al., suggested that AMH may be used as a marker in the diagnosis in PCOS women with oligomenorrhea [43].

\section{Conclusion}

Our results confirmed that $\mathrm{AMH}$ is high significantly correlated with AFC and with OV. The accuracy of the AMH as an easy diagnostic tool plus the presentable clinical symptoms for diagnosis of PCOS could replace all other diagnostic biochemical tests and ultrasound diagnosis especially in virgins as $\mathrm{AMH}$ measurement could predict PCOS morphology as there is a tight positive correlation between $\mathrm{AMH}$ and $\mathrm{AFC}$ and $\mathrm{OV}$.

Acknowledgement: Thanks to Dr. Laila Rashed for the biochemical analysis.

Limitation of this study: The small number of cases and controls gave limitations to this study and this is because the present work was not supported by any research grant.

Declaration of interest: The authors report no conflicts of interest. The authors are the sole responsible for the content and writing of the paper.

\section{References}

1-Boyle J, Cunningham, J, O'Dea K, .Dunbar T. Prevalence of polycystic ovary syndrome in a sample of Indigenous women in Darwin, Australia. Medical Journal of Australia. 2012; 196: 62-6.

2-March W, Moore V, Willson M. The prevalence of polycystic ovary syndrome in a community sample assessed under contrasting diagnostic criteria. Human Reprod. 2010; 25: 544-51.

3-Rotterdam ESHRE/ASRM-Sponsored PCOS Consensus Workshop Group. Revised 2003 consensus on diagnostic criteria and long-term health risks related to polycystic ovary syndrome. Fertil Steril. 2004; 81:19-25.

4-Dumesic D and Lobo R. Cancer risk and PCOS. Steroids. 2013; 78:782-85.

5-Veltman-Verhulst S., Boivin J., Eijkemans M., Fauser B. Emotional distress is a common risk in women with polycystic ovary syndrome: a systematic review and meta-analysis of 28 studies. Hum Reprod Update. 2012;18: 638-651.

6-Diamanti-Kandarakis E, Kandarakis H, Legro R. The role of genes and environment in the etiology of PCOS. Endocrine. 2006; 1: 19-26.

7-Pigny P, Merlen E, Robert Y, Cortet-Rudelli C, Decanter C, Jonard S, Dewailly D. Elevated serum level of anti-Müllerian hormone in patients with polycystic ovary syndrome: relationship to the 
ovarian follicle excess and to the follicular arrest. J Clin Endocrinol Metab. 2003; 88:5957-62.

8-Weenen C, Laven J, Von Bergh A, Cranfield M, Groome N, Visser J et al., Anti-Mullerian hormone expression pattern in the human ovary: potential implications for initial and cyclic follicle recruitment. Mol Hum Reprod. 2004; 10:77-83.

9-Fanchin R, Taieb J, Lozano D, Ducot B, Frydman R, Bouyer J. High reproducibility of serum antiMullerian hormone measurements suggests a multistaged follicular secretion and strengthens its role in the assessment of ovarian follicular status. Hum Reprod. 2005; 20:923-9.

10-Andersen C, Schmidt K, Kristensen S, Rosendahl M, Byskov A, Ernst E. Concentrations of AMH and inhibin-B in relation to follicular diameter in normal human small antral follicles. Hum Reprod. 2010; 25:1282-7.

11-Lutchman S, Muttukrishna S, Stein R, McGarrigle $\mathrm{H}$, Patel A, et al., Predictors of ovarian reserve in young women with breast cancer. $\mathrm{Br} \mathrm{J}$ Cancer. 2007;96:1808-16.

12-Kelsey T, Wright P, Nelson S, Anderson R, Wallace W. A validated model of serum Anti-Müllerian hormone from conception to menopause. PLoS One. 2011; 6:e22024.

13-De Vet A, Laven J, de Jong F, Themmen A, Fauser B. Anti-Müllerian hormone serum levels: a putative marker for ovarian aging. Fertil Steril . 2002;77:35762.

14-Jonard S, Robert Y, Cortet-Rudelli C, Pigny P, Decanter C, Dewailly D. Ultrasound examination of polycystic ovaries: is it worth counting the follicles? Hum Reprod. 2003;18:598-603.

15-ESHRE/ASRM. Revised Rotterdam 2003 consensus on diagnostic criteria and long-term health risks related to polycystic ovary syndrome (PCOS). Human Reproduction.2004; 19, 41-7.

16-Balen A, Laven J, Tan S, Dewailly D. Ultrasound assessment of the polycystic ovary: international consensus definitions. Hum Reprod Update. 2003; 9:505-14.

17-Rustamov O., Smith A., Roberts S. The measurement of Anti-Müllerian hormone: a critical appraisal. J. Clin. Endocrinol Metabol, 2014; 99: 723-32.

18-Hutchison S., Stepto N., Harrison C. Effects of exercise on insulin resistance and body composition in overweight and obese women with and without polycystic ovary syndrome. J Clin Endocrinol Metabol. 2011; 96: 48-56.

19-TeedeH, Misso M, Deeks A. Assessment and management of polycystic ovary syndrome: summary of an evidence-based guideline. Med Journal of Australia. 2011; 195: 69-111.

20-Goldenberg $\mathrm{N}$ and Glueck C. Medical therapy in women with polycystic ovary syndrome before and during pregnancy and lactation. Minerva Ginecol. 2008; 60: 63-75.

21-Teede H, Deeks A, Moran L. Polycystic ovary syndrome: a complex condition with psychological, reproductive and metabolic manifestations that impact on health across the lifespan. BMC Med. 2010; 8: 41 .

22-Somunkiran A, Yavuz T, Yucel O, Ozdemir I. AntiMüllerian hormone levels during hormonal contraception in women with polycystic ovary syndrome. Eur J Obstet Gynecol Reprod Bio. 2007; 134:196-201.

23-Lee D, Park S, Park S, Lee S, Chung $\mathrm{H}$, and Kyungah J . Clinical and Biochemical Profiles according to Homeostasis Model Assessment-insulin Resistance (HOMA-IR) in Korean Women with Polycystic Ovary Syndrome. J Menopausal Med. 2014; 20: 104-10.

24-Alebić M, Bulum T, Stojanović N, Duvnjak L. Definition of insulin resistance using the homeostasis model assessment (HOMA-IR) in IVF patients diagnosed with polycystic ovary syndrome (PCOS) according to the Rotterdam criteria. Endocrine. 2014; 47:625-30.

25-Suresh S. and VijayakumarT .Correlations of Insulin Resistance and Serum Testosterone Levels with LH: FSH Ratio and Oxidative Stress in Women with Functional Ovarian Hyperandrogenism. Indian J ClinBiochem. 2015; 30: 345-50.

26-Escobar-Morreale H, Carmina E, DewaillyD, Gambineri A. Epidemiology, diagnosis and management of hirsutism: a consensus statement by the Androgen Excess and Polycystic Ovary Syndrome Society. Hum Reprod Update.2012; 18:146-70.

27-Api M, Badoglu B, Akca A, Api O, Gorgen H, Cetin A. Inter observer variability of modified FerrimanGallwey hirsutism score in a Turkish population. Arch Gynecol Obstet. 2009; 279: 473-9.

28-Yildiz B, Bolour S, Woods K, Moore A, Azziz R. Visually scoring hirsutism. Hum Reprod Update. 2010; 16: 51-64.

29-Gambineri A, Repaci A, Patton L, Grassi I, Pocognoli P, et al., Prominent role of low HDLcholesterol in explaining the high prevalence of the metabolic syndrome in polycystic ovary syndrome. Nutr.Met.Card.Dis.2009;19:797-804.

30-Moran L., Harrison C., Hutchison S. et al., Exercise decreases Anti-Müllerian hormone in anovulatory overweight women with polycystic ovary syndrome: a pilot study. Hormone Metabol Res. 2011; 43: $977-$ 9.

31-Dewailly D, Gronier H, Poncelet E. Diagnosis of polycystic ovary syndrome (PCOS): revisiting the threshold values of follicle count on ultrasound and of the serum AMH level for the definition of polycystic ovaries. Hum Reprod. 2011; 26:3123-9. 
32-Laven J, Mulders A, Visser J, Themmen A, de Jong F, Fauser B. Anti-Müllerian hormone serum concentrations in normoovulatory and anovulatory women of reproductive age. J. Clin. Endocrinol. Metab. 2004; 89:318-23.

33-Piltonen T, Morin-Papunen L, Koivunen R, Perheentupa A. Serum anti-Müllerian hormone levels remain high until late reproductive age and decrease during metformin therapy in women with polycystic ovary syndrome. Human Reprod. 2005; 20: 1820-6.

34-Lin Y, Chiu W, Wu C, Tzeng C, Sen H, Hsu M. Anti-Müllerian hormone and polycystic ovary syndrome. Fertil. Steril. 2011;96:230-5.

35-Wiweko B, Maidarti M, Priangga M, Shafira N, Fernando D. Anti-Müllerian hormone as a diagnostic and prognostic tool for PCOS patients. $\underline{\mathbf{J}}$ Assist Reprod Genet. 2014; 31: 1311-6.

36-Amner S, Li T, Ledger W. The value of measuring Anti-Müllerian hormone in women with anovulatory polycystic ovary syndrome undergoing laparoscopic ovarian diathermy. Hum. Reprod. 2009; 24:2760-6.

37-Chen Y, Li L, Chen X, Zhang Q, Wang W, Li Y, Yang D. Ovarian volume and follicle number in the diagnosis of polycystic ovary syndrome in Chinese women. Ultrasound Obstet Gynecol. 2008; 32: 700-3.

38-Kosus N, Kosus A, Turhan N, Kamalak Z. Do threshold values of ovarian volume and follicle number for diagnosing polycystic ovarian syndrome in Turkish women differ from western countries? Eur J Obstet Gynecol Reprod Biol. 2011;154: 177-81.

39-Lujan M, Didier D, Enrico C, Marcelle C, Joop L, Robert J. Definition and significance of polycystic ovarian morphology: a task force report from the Androgen Excess and Polycystic Ovary Syndrome Society Human Reproduction Update. 2013; 20: 334-352.

40-Dewailly D, Andersen C, Balen A, Broekmans F, Dilaver N, et al., The physiology and clinical utility of anti-Mullerian hormone in women. Hum Reprod Update. 2014; 20:370-85.

41-Koutlaki N, Dimitraki M, Zervoudis S, Poiana

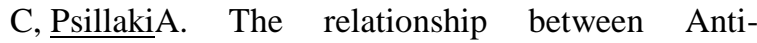
Müllerian hormone and other reproductive parameters in normal women and in women with polycystic ovary syndrome. J Med Life. 2013; 6: 146-50.

42-Matsuzaki T, Munkhzaya M, Iwasa T, Tungalagsuvd A et al. Relationship between serum Anti-Müllerian hormone and clinical parameters in polycyctic ovary syndrome. Endocrine Journal. 2017; 64:531-541.

43-Zhang F, Du J , Bin Wang B , Wen H , Jia X ,Chen $\mathrm{H}$, Deng X. Dynamics of hormonal profile and AntiMüllerian hormone during spontaneous ovulation in PCOS women with oligomenorrhea. Biomedical Research 2017; 28: 2491-2497 